\title{
Role of c-Met in the progression of human oral squamous cell carcinoma and its potential as a therapeutic target
}

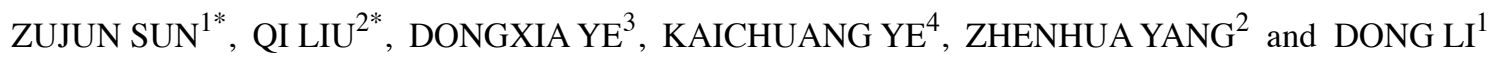 \\ ${ }^{1}$ Department of Clinical Laboratory, Shanghai Tongji Hospital, Tongji University School of Medicine, \\ Shanghai 200065; ${ }^{2}$ Department of Clinical Laboratory, Baoshan Traditional Chinese and Western Medicine \\ Hospital, Shanghai 201900; ${ }^{3}$ Shanghai Research Institute of Stomatology and ${ }^{4}$ Vascular Surgery, \\ Ninth People's Hospital, Shanghai Jiaotong University, School of Medicine, Shanghai 200011, P.R. China
}

Received May 12, 2017; Accepted October 10, 2017

DOI: $10.3892 /$ or.2017.6073

\begin{abstract}
Mesenchymal-epithelial transition factor (c-Met) is the only high affinity receptor for hepatocyte growth factor (HGF), and is frequently activated in many human cancers. However, little is known about the role of the HGF/c-Met signaling pathway in the progression of human oral squamous cell carcinoma (OSCC). This study evaluated the role of the HGF/c-Met signaling pathway in the progression of human OSCC. We found that the expression of c-Met was significantly increased in human OSCC tissues than in normal mucosa adjacent to the tumor $(\mathrm{P}<0.05)$, but was not correlated with clinicopathological parameters. Additionally, the selective c-Met inhibitor JNJ was found to inhibit cell viability and migration and promote apoptosis in OSCC cell lines, and also blocked the activation AKT, ERK1/2, and NF- $\mathrm{BB}$ p65; thus, suggesting that HGF/c-Met signaling may play an important role in the tumorigenic properties of OSCC cells via the AKT, ERK $1 / 2$, and $N F-\kappa B$ pathways. Collectively, these results indicated that $\mathrm{HGF} / \mathrm{c}-\mathrm{Met}$ signaling may serve essential roles in the progression of human OSCC, and may thus be a basis for the development of novel therapeutic approaches in the treatment of OSCC.
\end{abstract}

\section{Introduction}

Oral squamous cell carcinoma (OSCC) is among the most prevalent malignant neoplasms worldwide, and frequently occurs in developing countries, including those of Southeast

Correspondence to: Dr Dong Li or Dr Zujun Sun, Department of Clinical Laboratory, Shanghai Tongji Hospital, Tongji University School of Medicine, P.O.Box 218, 389 Xin Cun Road, Shanghai 200065, P.R. China

E-mail: 1861d@163.com

E-mail: sunzujun1976@126.com

*Contributed equally

Key words: c-Met, hepatocyte growth factor, oral squamous cell carcinomas
Asia $(1,2)$. Despite recent advances in surgical and radiotherapeutic strategies, a high proportion of patients with OSCC still have poor prognosis, which has remained relatively unchanged over the past 20 years $(3,4)$. Therefore, it is necessary to explore novel molecular targets for the development of more effective therapeutic strategies for patients with OSCC.

Mesenchymal-epithelial transition factor (c-Met) is the only known high-affinity receptor for hepatocyte growth factor (HGF). The HGF/c-Met signaling pathway can stimulate the growth of hepatocytes, and may also promote proliferation, migration, survival, angiogenesis, and invasion in a broad range of human solid tumors, including ovarian, stomach, lung, breast, liver, and brain tumors (5-12). Moreover, high expression of c-Met was found in pancreatic cancer stem cells, and knockdown of c-Met or treatment with a c-Met inhibitor blocked the formation of tumor spheres in a population of pancreatic cancer cells with stem cell like properties $(13,14)$. Furthermore, inhibition of the c-Met signaling pathway has been reported to increase mitochondrial release of cytochrome $c$ and the Bax/Bcl-2 ratio (15). These data regarding the aberrant expression and activity of c-Met revealed that it may play an important role in the progression of human cancers, and may be an important target in cancer therapy. However, little is known about the biological functions of the HGF/c-Met signaling pathway in the progression of human OSCC.

To elucidate the underlying functions of the HGF/c-Met signaling pathway in the progression of OSCC, the present study first examined c-Met expression in 40 human OSCC tissues, 20 human normal oral mucosa and two OSCC cell lines. Subsequently, we evaluated the effects of a c-Met inhibitor on the viability, migration, and apoptosis of the OSCC cell lines. Finally, we preliminarily investigated the potential molecular mechanisms underlying the activity of the $\mathrm{HGF} / \mathrm{c}-\mathrm{Met}$ signaling pathway in the progression of OSCC.

\section{Materials and methods}

Cell lines and cell culture conditions. The human HIOEC, HN30 and CAL-27 cell lines were obtained from the Laboratory of Oral Oncology, Ninth People's Hospital, School of Medicine, Shanghai Jiaotong University, Shanghai, China. The three cell lines were cultured in DMEM and medium 
supplemented with 10\% FBS (Gibco, Grand Island, NY, USA) and of $1 \%$ penicillin/streptomycin (Gibco). Cells were incubated at $37^{\circ} \mathrm{C}$ in a humidified incubator containing $5 \% \mathrm{CO}_{2}$.

Reagents and antibodies. Human recombinant HGF was purchased from GenScript (Nanjing, China). The c-Met kinase inhibitors JNJ38877605 (JNJ) was obtained from Selleckchem (Houston, TX, USA). Antibodies used included: Met mAb (\#8198), phosphor-Met (Tyr1234/1235) mAb (\#3077), AKT mAb (\#9272), phosphor-AKT (Ser473) mAb (\#4060), p44/42 MAP kinase mAb (\#4696), phosphor-p44/42 MAP kinase (Thr202/ Tyr204) mAb (\#4376), NF- $\mathrm{kB}$ p65 mAb (\#6131), GAPDH mAb (\#2118), MMP-9 mAb (\#3852), HRP-linked anti-mouse IgG antibody (\#7076), and HRP-linked anti-rabbit IgG antibody (\#7074). The PE-labeled anti-rabbit IgG antibody was used as a secondary antibody. All antibodies were purchased from Cell Signaling Technology, Inc. (Danvers, MA, USA). VEGF mAb (\#19003) was purchased from Proteintech (Chicago, IL, USA).

Immunohistochemistry (IHC). IHC was performed as previously described (16). Forty human OSCC specimens were collected from patients who had undergone surgery between September 2009 and September 2010 at the Department of Oral and Maxillofacial Surgery, Ninth People's Hospital, School of Medicine, Shanghai Jiao Tong University. All experimental procedures received ethics approval from the independent Ethics Committee of the Shanghai Ninth People's Hospital Affiliated to Shanghai Jiaotong University School of Medicine (no. 200926). The pathological characterization of the OSCC patients included in this study is summarized in Table I. For immunohistochemical examination, tissues were fixed with $4 \%$ paraformaldehyde and embedded with paraffin. Sections of the samples were blocked with $10 \%$ goat serum in PBS and incubated overnight at $4^{\circ} \mathrm{C}$ with anti-c-Met, anti-VEGF-A or anti-MMP-9 antibodies. After 3 washes with PBS, the sections were incubated with the peroxidase-conjugated goat anti-rabbit antibody for $1 \mathrm{~h}$, following by incubation with 3,3'-diaminobenzidine (DAB) substrate for $3 \mathrm{~min}$. Counter-staining was performed with hematoxylin, and dehydration was then performed with ethanol and dimethyl benzene. The IHC results in tissues were scored by two independent investigators based on the level of staining intensity as follows: none (-), $0 \%$ of stained cells; weak $(+), 1-25 \%$ of stained cells; moderate $(++)$, $26-50 \%$ of stained cells; strong $(+++),>50 \%$ of stained cells.

RNA isolation and RT-PCR. Total RNA was isolated and RT-PCR was performed as previously described (16). The primer pairs were as follows: c-Met, forward 5'-TTC-ACC-GCG-GAA-ACA-CCC-ATC-3', and reverse 5'-GTC-TTC-CAG-CCA-GGC-CCA-3'; GAPDH, forward 5'-CAT-CTC-TGC-CCC-CTC-TGC-TGA-3', and reverse 5'-GGA-TGA-CCT-TGC-CCA-CAG-CCT-3'.

Western blotting. Western blot analysis was performed as previously described (16). The cells were lysed with M-PER ${ }^{\circledR}$ mammalian protein extraction (Pierce, Rockford, IL, USA). Proteins were quantified by the BCA Protein Assay kit (Pierce) according to the manufacturer's instructions. Samples containing a total of $50 \mu \mathrm{g}$ protein were incubated at $100^{\circ} \mathrm{C}$ for $5 \mathrm{~min}$, separated by SDS-polyacrylamide gel electrophoresis, and subsequently electrotransferred onto a polyvinylidene difluoride membrane. Essential component detection in the cells was performed using an antibody with overnight incubation at $4^{\circ} \mathrm{C}$, and then an HRP-conjugated secondary antibody (1:5,000 dilution) was added for $1 \mathrm{~h}$ at room temperature, followed by the development of reactions in a chemiluminescent detection system.

Viability and apoptosis assays. Cells were seeded in a 96-well plate at $1 \times 10^{4}$ cells/well and were grown in the presence of JNJ for $2 \mathrm{~h}$. Then, they were treated with HGF. After 3 days, $20 \mu \mathrm{l}$ MTS (Sango, Shanghai, China) was added to each sample and incubated for $4 \mathrm{~h}$. The absorbance of the solution was recorded at $490 \mathrm{~nm}$ with a Thermo microplate reader. The results of the MTS assay reflected the cell viability.

Apoptotic cells were assessed by flow cytometry as follows: cells were harvested and washed with PBS, resuspended in pre-diluted binding buffer, and stained with Annexin V-FITC (BD Biosciences, San Diego, CA, USA) for $30 \mathrm{~min}$ at room temperature. After being washed and resuspended in PI binding buffer, the cells were immediately subjected to apoptosis analyses by flow cytometry using Cell Quest Software.

In vitro scratch wound healing migration assays. $\mathrm{HN} 30$ or CAL-27 cells were plated in a 6-well plate. After overnight incubation, a sterile $10 \mu \mathrm{l}$ pipette tip was used to make a wound across a cell culture monolayer. Cells were incubated in DMEM-0\% FBS in the presence of JNJ for $2 \mathrm{~h}$, and then were treated with HGF $(100 \mathrm{ng} / \mathrm{ml})$. Multiple images of the wound were taken immediately after wounding at 0 and $24 \mathrm{~h}$ under a phase-contrast microscope. The efficiency of the wound healing process was determined by calculating the area of the cell gap at the indicated time-points ( 0 and $24 \mathrm{~h}$ ), using ImageJ software. Three images were used for each wound at each experimental point. The results are expressed as percentage of healing at $24 \mathrm{~h}$ with respect to time-point zero.

Immunofluorescence analysis. Tumor cells deposited on glass slides were washed twice with PBS and fixed in 4\% paraformaldehyde in PBS for $20 \mathrm{~min}$. The cells were further permeabilized with $0.1 \%$ Triton X in PBS for 8 min, washed and blocked with $5 \%$ bovine serum albumin in PBS for $30 \mathrm{~min}$, and then treated with a monoclonal mouse anti-p65 (Santa Cruz Biotechnology, Inc., Santa Cruz, CA, USA) antibody overnight. PE-labeled (1:100) anti-rabbit IgG served as the secondary antibody. The sections were then mounted in a medium containing DAPI for 5 min to visualize cell nuclei. The slides were evaluated with fluorescence microscope TCS SP2 (Leica, Wetzlar, Germany).

Tumor xenograft study. Approximately 5- to 6-week-old male athymic nude mice (approximately $20 \mathrm{~g}$ ) were obtained from SLAC Laboratory Animal Co., Ltd. (Shanghai, China) and were kept in a specific pathogen-free (SPF) facility. CAL-27 cells $\left(5 \times 10^{6}\right)$ were subcutaneously injected into the right flank region of mice. After 6 days, allowing the tumors to grow to approximately $50 \mathrm{~mm}^{3}$, the mice were randomized into control and treatment groups. For the CAL-27 xenograft, the mice were treated as follows: $\mathrm{JNJ}(10 \mathrm{mg} / \mathrm{kg})$ oral administration drugs once a day for 4 weeks. Each group consisted of 5-6 mice. Concomitantly, the body weight and tumor size 
Table I. The correlation between clinicopathological features and expression of c-Met.

\begin{tabular}{|c|c|c|c|c|}
\hline Characteristics & Case no. & c-Met positive grade & Non-parametric test value & P-value \\
\hline Tobacco & & & $Z=-0.588$ & 0.565 \\
\hline Yes & 17 & $1.25 \pm 1.09$ & & \\
\hline No & 23 & $1.04 \pm 1.12$ & & \\
\hline Alcohol & & & $Z=-0.271$ & 0.798 \\
\hline Yes & 18 & $1.17 \pm 1.04$ & & \\
\hline No & 22 & $1.09 \pm 1.15$ & & \\
\hline Sex & & & $Z=-0.062$ & 0.965 \\
\hline Male & 28 & $1.12 \pm 1.03$ & & \\
\hline Female & 12 & $1.17 \pm 1.13$ & & \\
\hline Tumor site & & & $\chi^{2}=0.318$, d.f $=3$ & 0.957 \\
\hline Oral cavity & 21 & $1.10 \pm 1.09$ & & \\
\hline Gingiva & 6 & $1.0 \pm 1.27$ & & \\
\hline Mouth floor & 7 & $1.29 \pm 1.11$ & & \\
\hline Other & 6 & $1.17 \pm 1.17$ & & \\
\hline Tumor stage & & & $\chi^{2}=1.698$, d.f $=3$ & 0.637 \\
\hline $\mathrm{T} 1$ & 17 & $1.18 \pm 1.13$ & & \\
\hline $\mathrm{T} 2$ & 12 & $0.92 \pm 0.99$ & & \\
\hline T3 & 6 & $1.33 \pm 1.21$ & & \\
\hline $\mathrm{T} 4$ & 5 & $1.20 \pm 1.30$ & & \\
\hline Nodal status & & & $Z=-0.987$ & 0.442 \\
\hline No & 27 & $1.07 \pm 1.12$ & & \\
\hline $\mathrm{N} 1-2$ & 13 & $1.23 \pm 1.09$ & & \\
\hline \multicolumn{5}{|l|}{ Pathological } \\
\hline differentiation grade & & & $\chi^{2}=0.505$, d.f $=2$ & 0.777 \\
\hline Well & 23 & $1.09 \pm 1.08$ & & \\
\hline Moderately & 13 & $1.08 \pm 1.11$ & & \\
\hline Poorly & 4 & $1.50 \pm 1.29$ & & \\
\hline
\end{tabular}

Z, non-parametric tests value; d.f., degree of freedom.

were assessed using an electronic balance and a vernier caliper. The tumor volume was calculated using the formula: volume $=\left(\right.$ length $\mathrm{x}$ width $\left.^{2}\right) \times 1 / 2$. Following the endpoint (28 days after the implantation), mice were euthanized when moribund for the collection of tumors. This study was performed via protocols approved by the Institutional Animal Care and Use Committee of Fudan University (Shanghai, China).

Statistical analysis. Statistical analysis was performed using SPSS 17.0 software (SPSS Inc., Chicago, IL, USA). Data are presented as the mean \pm standard deviation (SD) of at least three separate experiments. One-way ANOVA was performed with post hoc SNK for multiple comparisons. $\mathrm{P}<0.05$ was considered to indicate a statistically significant difference.

\section{Results}

Expression of c-Met in human OSCC tissues and cell lines. To investigate whether c-Met was expressed in human OSCC tissues,
40 human OSCC specimens and 20 normal oral tissue samples adjacent to the tumor were assessed by immunohistochemistry. A high level of c-Met expression was detected in 60\% (24/40) of the carcinoma samples, while only in $25 \%(5 / 20)$ of the normal oral epithelial tissues. In the tumor samples, c-Met was found to be localized in the cell membrane and cytoplasm (Fig. 1A). The expression of c-Met in situ was not correlated with patient clinicopathological characteristics, including tobacco use, alcohol consumption, sex, tumor site, tumor stage, nodal status or pathological differentiation grade (Table I). Additionally, we detected upregulated c-Met in HIOEC and the OSCC cell lines (HN30 and CAL-27) by RT-PCR and western blot analysis, as shown in Fig. 1B. Thus, the increased expression of c-Met in OSCC tissues and cell lines revealed that c-Met may be functionally important in the progression of human OSCC.

JNJ inhibits the effects of HGF on cancer cell viability, migration, and anti-apoptosis. Since the HGF/c-Met signaling pathway can mediate tumor growth, migration, 

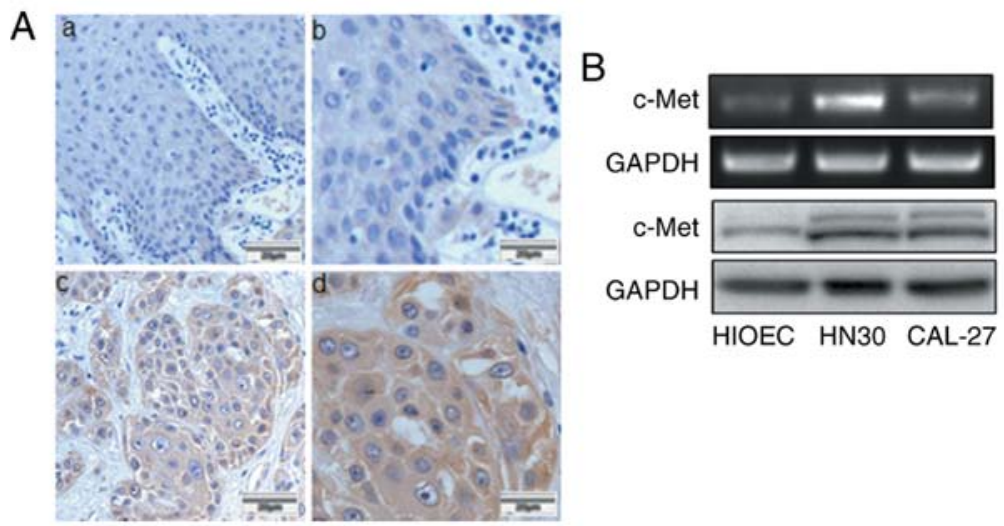

Figure 1. Expression of c-Met in human OSCC tissues and cell lines. (A) Representative immunohistochemical staining of c-Met expression in 20 human non-malignant epithelia (a) x100, (b) x400; and 40 OSCC tissues (c) x100 and (d) x400. (B) Analysis of c-Met expression in human OSCC cell lines by RT-PCR (upper panel) and western blotting (lower panel). GAPDH was used as an internal control.
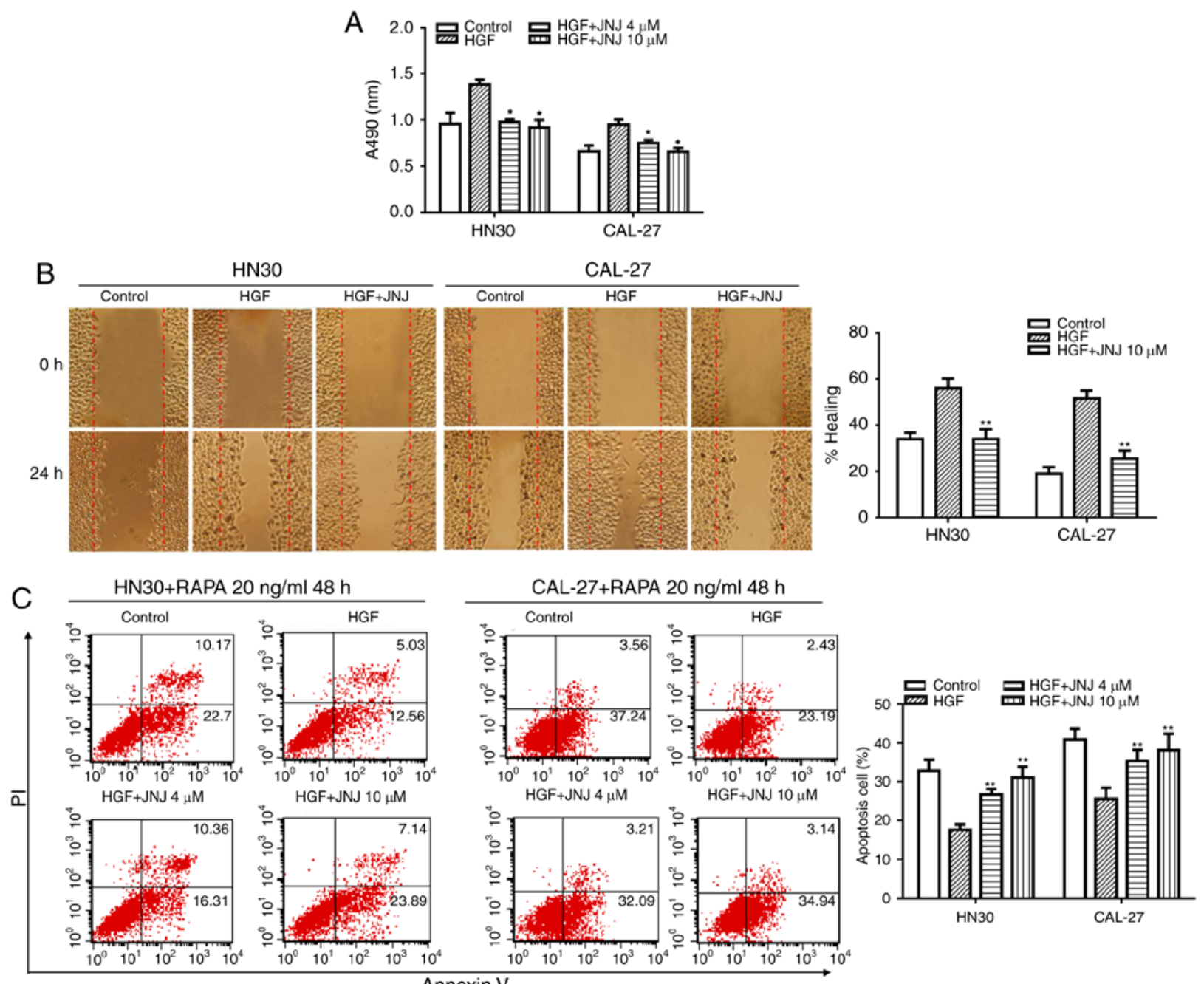

Figure 2. JNJ inhibits the pro-proliferative, pro-migratory, and anti-apoptotic effects of HGF. (A) The viability of HN30 and CAL-27 cells was assessed by MTS assay. (B) Wound healing assay. Cancer cells were cultured to confluence on plastic dishes, and the following day, linear scratch wounds were created with a sterile tip. Cell treatments were as described in Materials and methods (x100). (C) Cancer cells were incubated with JNJ for $2 \mathrm{~h}$ and then treated with different combinations of HGF (100 ng/ml) and RAPA $(20 \mathrm{ng} / \mathrm{ml})$. At $48 \mathrm{~h}$ post-treatment, apoptotic cells stained with Annexin V and propidium iodide were detected by flow cytometry. Data shown represent the means \pm SD of three independent experiments. ${ }^{*} \mathrm{P}<0.05,{ }^{* * *} \mathrm{P}<0.01$, compared with the HGF only treatment group.

invasion, and survival $(6,7)$, we first sought to assess the effect of JNJ on tumor cell viability. JNJ is a small-molecule
ATP-competitive inhibitor of the catalytic activity of c-Met, which exhibited $\sim 600$-fold selectivity for c-Met compared 

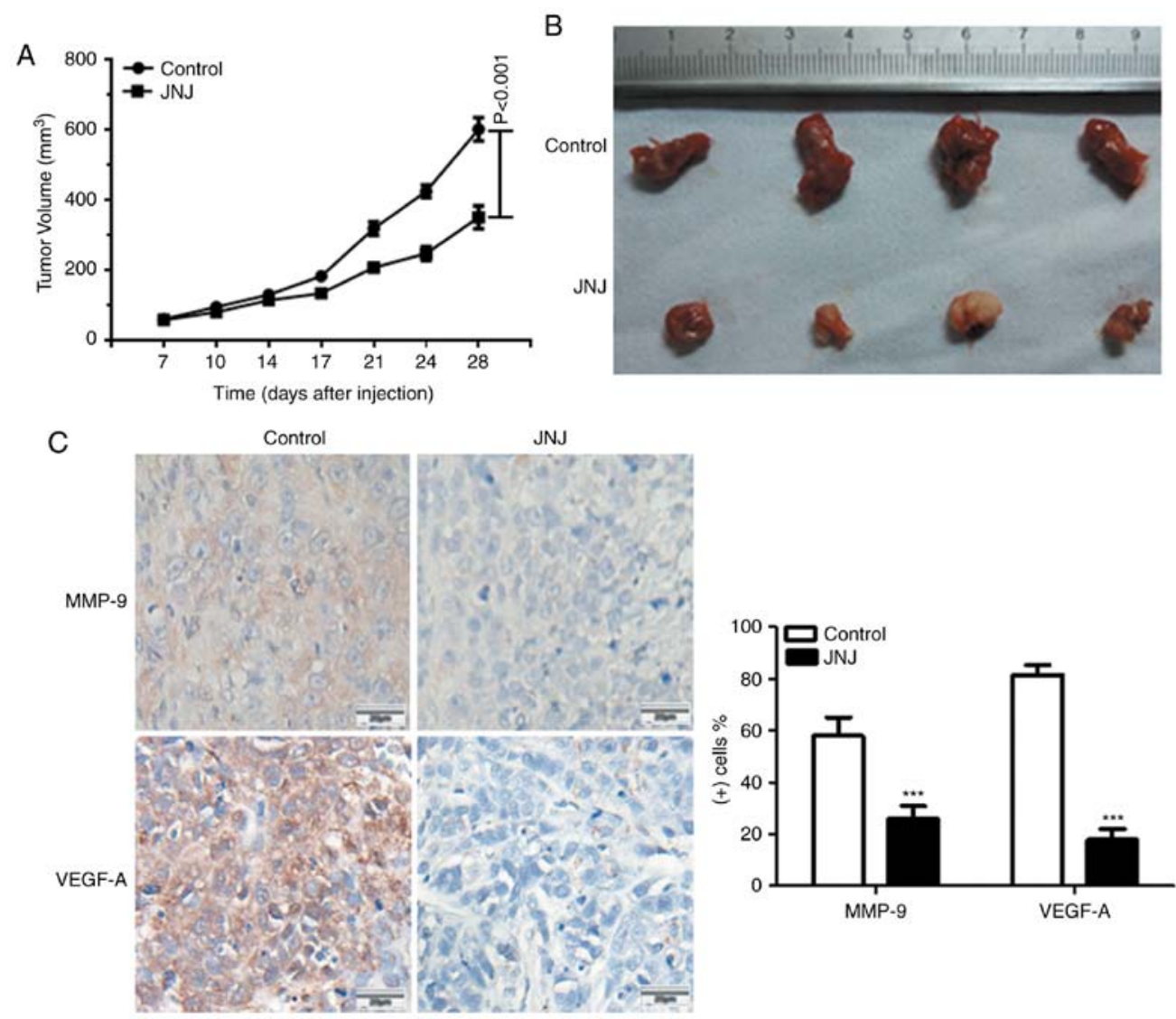

Figure 3. Therapeutic effect of JNJ in xenograft mice. (A) Xenograft studies were performed using 5-6 male nude mice $~ 5-6$ weeks old per group, and the tumor volumes were assessed on the indicated days. (B) Tumor xenografts of CAL-27 cells were removed 4 days after the last treatment. (C) Semi-quantification of immunohistochemistry results was expressed as the percentage of positively-stained cells. Representative staining of VEGF-A and MMP-9 in the isolated tumors is shown. Magnification, $\mathrm{x} 200 ;{ }^{* * *} \mathrm{P}<0.001$, compared with the control group.

with a panel of $\sim 250$ diverse tyrosine and serine-threonine kinases. It was also found to potently inhibit HGF-stimulated and constitutively activated c-Met phosphorylation (17). HN30 and CAL-27 cells were treated with or without JNJ for $2 \mathrm{~h}$ prior to treatment with HGF, and an MTS cell viability assay was performed subsequently. The results revealed that JNJ could significantly reverse the stimulatory effect of HGF on cancer cell viability (Fig. 2A). Next, the effect of JNJ on the migration of HN30 and CAL-27 cells was characterized. In a wound healing assay, it was observed that $\mathrm{JNJ}(10 \mu \mathrm{M})$ could significantly suppress HGF-induced migration of the tumor cells (Fig. 2B).

We also evaluated the effect of JNJ on c-Met signaling in the regulation of cancer cell death. HN30 and CAL-27 cells were treated with JNJ for $2 \mathrm{~h}$, and then with combinations of HGF and RAPA. After treatment for $48 \mathrm{~h}$, the cells were analyzed by flow cytometry to evaluate the apoptotic index. The results revealed that HGF could significantly rescue RAPA-induced HN30 cell apoptosis when compared with the control group. Notably, the percentage of RAPA-induced apoptotic cells was decreased from 32.87 to $17.59 \%$ following HGF stimulation of the cancer cells. In addition, pretreatment with JNJ could markedly supress the effect of HGF. Thus, following JNJ pretreatment, the percentage of apoptotic cells increased from 17.59 to $26.91 \%$ for the RAPA-induced + HGF-treated HN30 cells (Fig. 2C). The same phenomenon was observed in CAL-27 cells. Altogether, our results indicated that JNJ may play an important role in inhibiting the pro-proliferation, pro-migration, and anti-apoptotic effects of HGF in human OSCC cell lines.

JNJ inhibits tumor development in vivo. JNJ displayed excellent oral bioavailability approaching $100 \%$ in all examined species and JNJ in a single dose was observed to inhibit Met phosphorylation in tumor xenografts for up to $16 \mathrm{~h}$ (18). Finally, the therapeutic efficacy of JNJ was explored in mice in vivo. Following CAL-27 cell xenografts, the mice were treated with or without JNJ $(10 \mathrm{mg} / \mathrm{kg})$. As shown in Fig. 3A and B, JNJ treatment significantly reduced the tumor size when compared with the control group $(\mathrm{P}<0.001)$. We also found that JNJ could reduce the expression of VEGF-A and MMP-9, two key proteins related to angiogenesis and migration, which indicated its ability to inhibit cancer cell angiogenesis, migration, and invasion in vivo (Fig. 3C). These data collectively indicated the potency of JNJ in inhibiting tumor growth, angiogenesis, and migration in vivo.

JNJ inhibits HGF-mediated upregulation of c-Met downstream molecules. The PI3K/AKT and ERK signaling pathways act downstream of c-Met signaling, and thus we examined the effects of JNJ on these downstream pathways in HN30 and CAL-27 cells. Western blot analysis revealed that the HGF-mediated upregulation of p-c-Met in the cancer cells was abolished by JNJ treatment (Fig. 4A). In addition, upregulation of p-AKT was also observed in the cancer cells 
A
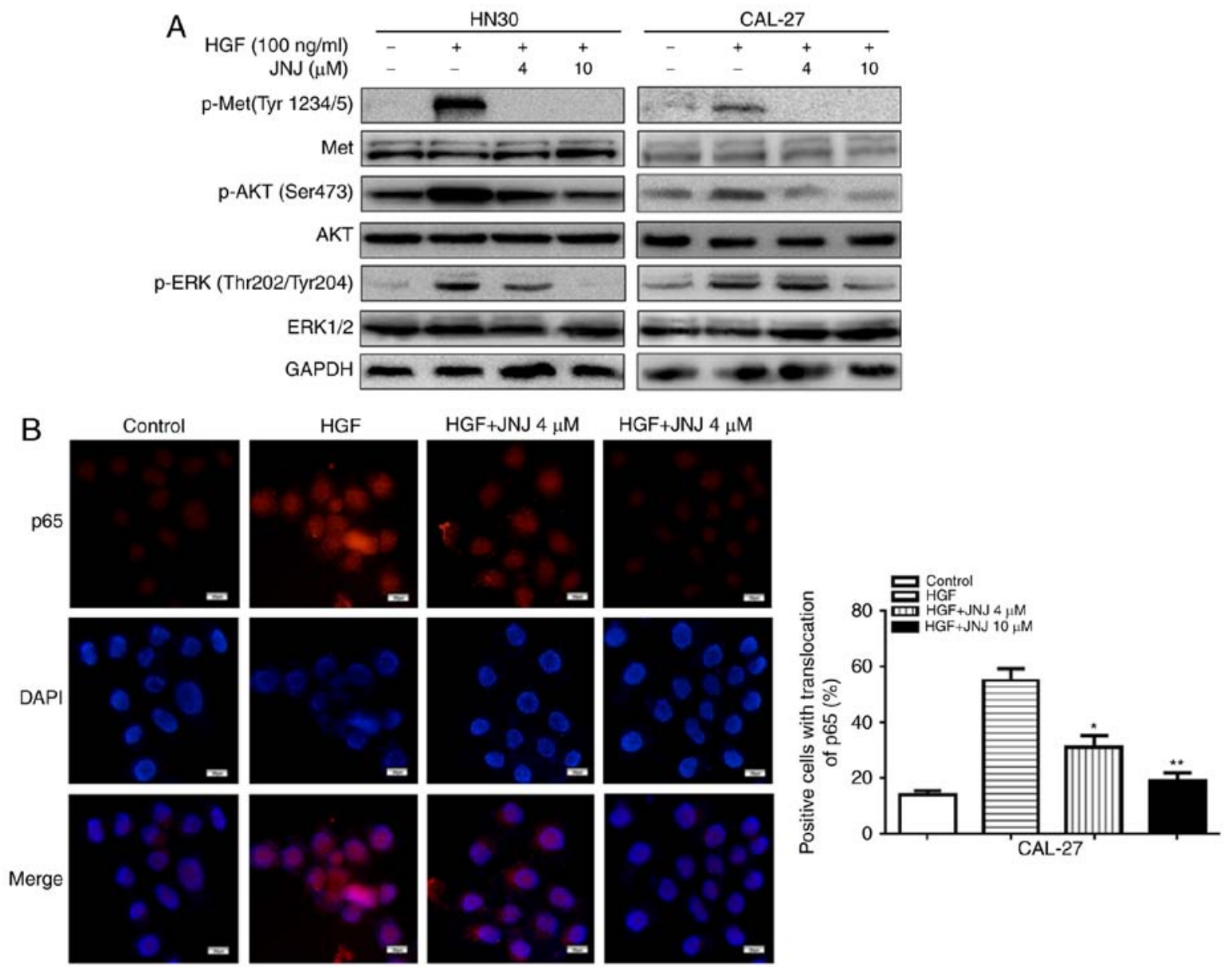

Figure 4. JNJ inhibits c-Met downstream molecules. (A) HN30 and CAL-27 cells were treated with the indicated concentrations of JNJ for $2 \mathrm{~h}$, and then stimulated with or without HGF $(100 \mathrm{ng} / \mathrm{ml})$ for $30 \mathrm{~min}$. Following treatment, total cell lysates were evaluated by western blotting using specific antibodies. (B) CAL-27 cells were treated with the indicated concentrations of JNJ for $2 \mathrm{~h}$, and then stimulated with or without HGF (100 ng/ml) for $30 \mathrm{~min}$. Following treatment, immunofluorescence analysis was performed as described in Materials and methods. The p 65 subunit of NF-kB is represented by red staining; the percentage of cells exhibiting p 65 translocation was determined from 200 randomly counted cells. The data represent the means \pm SD of three independent experiments. ${ }^{*} \mathrm{P}<0.05,{ }^{* *} \mathrm{P}<0.01$, compared with the HGF only treatment group.

in response to HGF stimulation, which was also inhibited by treatment with JNJ. Similarly, HGF-mediated upregulation of p-ERK1/2 was inhibited by JNJ. Meanwhile, in CAL-27 cells immunofluorescence staining indicated that there was a significant increase in the nuclear translocation of the NF- $\mathrm{BB}$ subunit p65 after HGF stimulation (Fig. 4B), which could also be significantly inhibited by JNJ treatment ( 4 and $10 \mu \mathrm{M}$ ). These results revealed that the AKT, ERK1/2, and NF- $\mathrm{BB}$ p65 pathways play essential roles in the growth, migration, and apoptosis of OSCC cells, possibly mediating the effects of JNJ on the inhibition of OSCC progression after targeting c-Met.

Cigarette smoking is considered to be among the major risk factors for OSCC (19). Additionally, cigarette smoking has been reported to induce overexpression of c-Met and HGF $(20,21)$. Collectively, with our results, these data revealed that c-Met expression may mediate smoking-induced OSCC progression. Therefore, inhibition of c-Met may be an effective strategy for preventing the progression of OSCC.

\section{Discussion}

It is well established that cigarette smoking is among the major factors that induce oral squamous cell carcinoma (OSCC) (19), and cigarette smokers have been reported to have a 2-5 times greater risk of developing oral cancer than non-smokers. Furthermore, the risk of oral cancer increases with the number of cigarettes smoked and the duration of smoking (20). In cigarette smokers, overexpression of c-Met has been found to be induced in microvessels of oral lichen planus, and the majority of smoker samples exhibit c-Met-positive expression (21). Additionally, it was reported that nicotine can induce HGF overexpression in lung cancer tissues, as well as in type II normal pneumocytes, while overexpression of c-Met was frequently detected in adenocarcinoma cells, and nicotine can enhance the pro-migratory effect of HGF on lung cancer cells, thus possibly contributing to lung cancer progression $(22,23)$.

A previous study on head and neck squamous cell carcinoma (HNSCC) demonstrated that c-Met-positive cells had cancer stem cell properties and could resist the effect of cisplatin (24). c-Met was upregulated and functional in $90 \%$ of HNSCC cell lines and $84 \%$ of patient samples $(25,26)$. It has also been suggested that the HGF/c-Met signaling pathway is associated with the progression and invasive behavior of OSCC (27-29). The length of survival was significantly reduced in oral tongue carcinoma patients with c-Met expression compared to those without c-Met expression (30). Activation of HGF/c-Met was 
critical for enhanced proliferation, invasion, and metastasis in HNSCC, which was correlated with decreased survival, increased recurrence rates and poor patient prognosis (31-33). c-Met knockdown in OSCC cell lines reduced cervical lymph node spread and increased survival of mice in an orthotopic animal model (34). However, the relationship between the $\mathrm{HGF} / \mathrm{c}-$ Met signaling pathway and the progression of OSCC is not fully understood. It is essential to understand the molecular mechanism so as to aid clinical intervention.

In the present study, we examined the degree of c-Met expression in OSCC tissues and its potential correlation with clinicopathological parameters. We found that $60.0 \%(24 / 40)$ of the OSCC tissues exhibited a high level of c-Met expression, whereas only $25 \%(5 / 20)$ of the normal oral epithelial tissues expressed c-Met. This result revealed that the c-Met protein was produced in the majority of OSCC cases. However, we found that there were no significant correlations between c-Met expression and clinicopathological variables, such as tobacco use, alcohol consumption, sex, tumor site, tumor stage, nodal status or pathological differentiation grade (Table I). Nevertheless, the aberrant expression of c-Met in OSCC samples compared with normal tissues revealed that it may play an important role in the progression of human OSCC. Cigarette smoking can induce overexpression of c-Met, which may in turn result in OSCC. However, there was no significant correlation between c-Met expression and cigarette smoking. This may be a limitation of the present study, as only 40 specimens of OSCC were investigated, and thus a larger number of specimens should be investigated in future studies.

Overexpression of c-Met has been reported in many types of cancer, and potentially leads to aberrant signaling associated with cancer development and progression (35,36). Activation of the $\mathrm{HGF} / \mathrm{c}-\mathrm{Met}$ signaling pathway promotes tumor cell proliferation, migration, and invasion and tumor angiogenesis, and was associated with poor prognosis (37-39). HGF can promoted tumor angiogenesis and reverse suspension-induced apoptosis (anoikis), which in turn, can increase not only tumor growth, but also tumor invasion and metastasis (40-44). To further investigate the role of the HGF/c-Met signaling pathway in the progression of OSCC, in vitro experiments were carried out in the present study. We found that c-Met was overexpressed in two OSCC cell lines (Fig. 1B), indicating that OSCC cell lines may obtain a growth advantage by upregulating c-Met. Exposure to a selective c-Met inhibitor, JNJ, had substantial effects on cell viability, migration, and apoptosis following HGF stimulation of the OSCC cell lines (Fig. 2A-C). HGF provides anoikis resistance to HNSCC cells, and anoikis resistance plays an important role in tumor progression and metastasis (41). Our results revealed that HGF can prolong cancer cell survival and promote metastasis by inhibiting apoptosis. Our findings demonstrated that OSCC cell lines can be stimulated to grow by HGF stimulation, and thus c-Met may be aberrantly activated in the progression of OSCC.

HGF can induce c-Met phosphorylation, which in turn activates multiple downstream pathways, including the PI3K/AKT and MAPK/ERK signaling pathways $(6,40)$. c-Met inhibitors have demonstrated antitumor efficacy in preclinical studies and are currently being evaluated in human cancer clinical trials $(45,46)$. In the present study, the selective c-Met inhibitor
JNJ exerted antitumor effects on OSCC cell growth potentially by blocking activation of AKT, ERK, and NF- $\kappa$ B p65 (Fig. 4A and B). These data indicated that activation of the HGF/c-Met system may stimulate cancer cell survival and growth through the ERK, PI3K/AKT, and NF- $\mathrm{B}$ signaling pathways.

In summary, our results ascetaoned that JNJ can inhibit HGF-stimulated cell viability and migration, and further confirmed the potent opposing activity of JNJ against the antiapoptotic effect of HGF. These findings indicated the potential role of c-Met in the progression of OSCC. The HGF/c-Met system functions as a potent pro-growth signal that exacerbates the malignant progression of OSCC. Thus, c-Met inhibition is considered to exert a potent pro-apoptotic effect as part of its direct impact on OSCC. Accordingly, our data revealed that JNJ inhibited HGF-induced survival of the OSCC cell lines in vitro. In particular, JNJ markedly inhibited the proproliferative, pro-migration, and anti-apoptotic effects of HGF by inhibiting the c-Met pathway. JNJ also inhibited tumor growth, angiogenesis, and migration in OSCC xenografts (Fig. 3A-C). The expression of Ki-67 related to tumor proliferation was also analyzed. However, for some reason, there were no differences between the control and JNJ-treated group. In addition, immunohistochemical staining of human OSCC tissues revealed high expression of c-Met. Therefore, we have not only demonstrated the pro-proliferative, pro-promigratory, and anti-apoptotic activity of $\mathrm{HGF} / \mathrm{c}-$ Met signaling in OSCC cells, but also provided solid data on the possible molecular mechanisms mediating such activity, which may serve important roles in the progression of OSCC. Therefore, c-Met may be an important target for the development of new therapeutic approaches in the treatment of OSCC.

\section{Acknowledgements}

This study was supported by the National Natural Science Foundation of China (81001205, 81202132, 81472179, 81500371) and the Three-year Planning for Strengthening the Construction of Public Health System in Shanghai (2015-2017) (15GWZK0301).

\section{References}

1. Kademani D: Oral cancer. Mayo Clin Proc 82: 878-887, 2007.

2. Petersen PE: The World Oral Health Report 2003: Continuous improvement of oral health in the 21 st century - the approach of the WHO Global Oral Health Programme. Community Dent Oral Epidemiol 31 (Suppl 1): 3-23, 2003.

3. Jemal A, Siegel R, Ward E, Hao Y, Xu J, Murray T and Thun MJ: Cancer statistics, 2008. CA Cancer J Clin 58: 71-96, 2008.

4. Lothaire P, de Azambuja E, Dequanter D, Lalami Y, Sotiriou C, Andry G, Castro G Jr and Awada A: Molecular markers of head and neck squamous cell carcinoma: Promising signs in need of prospective evaluation. Head Neck 28: 256-269, 2006.

5. Cecchi F, Rabe DC and Bottaro DP: Targeting the HGF/Met signalling pathway in cancer. Eur J Cancer 46: 1260-1270, 2010.

6. Birchmeier C, Birchmeier W, Gherardi E and Vande Woude GF: Met, metastasis, motility and more. Nat Rev Mol Cell Biol 4: 915-925, 2003.

7. Trusolino L and Comoglio PM: Scatter-factor and semaphorin receptors: Cell signalling for invasive growth. Nat Rev Cancer 2: 289-300, 2002.

8. Maulik G, Shrikhande A, Kijima T, Ma PC, Morrison PT and Salgia R: Role of the hepatocyte growth factor receptor, c-Met, in oncogenesis and potential for therapeutic inhibition. Cytokine Growth Factor Rev 13: 41-59, 2002. 
9. Laterra J, Nam M, Rosen E, Rao JS, Lamszus K, Goldberg ID and Johnston P: Scatter factor/hepatocyte growth factor gene transfer enhances glioma growth and angiogenesis in vivo. Lab Invest 76: 565-577, 1997.

10. Mhawech-Fauceglia P, Afkhami M and Pejovic T: MET/HGF signaling pathway in ovarian carcinoma: Clinical implications and future direction. Pathol Res Int 2012: 960327, 2012

11. Chu JS, Ge FJ, Zhang B, Wang Y, Silvestris N, Liu LJ, Zhao CH, Lin L, Brunetti AE, Fu YL, et al: Expression and prognostic value of VEGFR-2, PDGFR- $\beta$, and c-Met in advanced hepatocellular carcinoma. J Exp Clin Cancer Res 32: 16-23, 2013.

12. Landi L, Minuti G, D'Incecco A and Cappuzzo F: Targeting c-MET in the battle against advanced nonsmall-cell lung cancer. Curr Opin Oncol 25: 130-136, 2013.

13. Li C, Wu JJ, Hynes M, Dosch J, Sarkar B, Welling TH, Pasca di Magliano M and Simeone DM: c-Met is a marker of pancreatic cancer stem cells and therapeutic target. Gastroenterology 141: 2218-2227.e5, 2011.

14. Herreros-Villanueva M, Zubia-Olascoaga A and Bujanda L: c-Met in pancreatic cancer stem cells: Therapeutic implications. World J Gastroenterol 18: 5321-5323, 2012.

15. Liu Y, Liu JH, Chai K, Tashiro S, Onodera S and Ikejima T: Inhibition of c-Met promoted apoptosis, autophagy and loss of the mitochondrial transmembrane potential in oridonin-induced A549 lung cancer cells. J Pharm Pharmacol 65: 1622-1642, 2013.

16. Sun Z, Hu S, Luo Q, Ye D, Hu D and Chen F: Overexpression of SENP3 in oral squamous cell carcinoma and its association with differentiation. Oncol Rep 29: 1701-1706, 2013.

17. Perera T, Lavrijssen T, Janssens B, Geerts T, King P, Mevellec L, Cummings M, Lu T, Johnson D and Page M: JNJ-38877605: A selective Met kinase inhibitor inducing regression of Met-driven tumor models. Presented at the 99th AACR Annual Meeting, Apr 12-16, 2008, San Diego, CA, USA: 4837.

18. Torti D, Sassi F, Galimi F, Gastaldi S, Perera T, Comoglio PM, Trusolino L and Bertotti A: A preclinical algorithm of soluble surrogate biomarkers that correlate with therapeutic inhibition of the MET oncogene in gastric tumors. Int J Cancer 130: $1357-1366,2012$

19. Weiner D, Khankin EV, Levy Y and Reznick AZ: Effects of cigarette smoke borne reactive nitrogen species on salivary alpha-amylase activity and protein modifications. J Physiol Pharmacol 60 (Suppl 5): 127-132, 2009.

20. Wald NJ and Hackshaw AK: Cigarette smoking: An epidemiological overview. Br Med Bull 52: 3-11, 1996.

21. Kłosek SK, Sporny S, Stasikowska-Kanicka O and Kurnatowska AJ: Cigarette smoking induces overexpression of c-Met receptor in microvessels of oral lichen planus. Arch Med Sci 7: 706-712, 2011.

22. Chen JT, Lin TS, Chow KC, Huang HH, Chiou SH, Chiang SF, Chen HC, Chuang TL, Lin TY and Chen CY: Cigarette smoking induces overexpression of hepatocyte growth factor in type II pneumocytes and lung cancer cells. Am J Respir Cell Mol Biol 34: 264-273, 2006

23. Yoneyama R, Aoshiba K, Furukawa K, Saito M, Kataba H, Nakamura $\mathrm{H}$ and Ikeda $\mathrm{N}$ : Nicotine enhances hepatocyte growth factor-mediated lung cancer cell migration by activating the $\alpha 7$ nicotine acetylcholine receptor and phosphoinositide kinase-3dependent pathway. Oncol Lett 11: 673-677, 2016.

24. Sun S and Wang Z: Head neck squamous cell carcinoma c-Met ${ }^{+}$ cells display cancer stem cell properties and are responsible for cisplatin-resistance and metastasis. Int J Cancer 129: 2337-2348, 2011.

25. Seiwert TY, Jagadeeswaran R, Faoro L, Janamanchi V, Nallasura V, El Dinali M, Yala S, Kanteti R, Cohen EE, Lingen MW, et al: The MET receptor tyrosine kinase is a potential novel therapeutic target for head and neck squamous cell carcinoma. Cancer Res 69: 3021-3031, 2009.

26. De Herdt MJ and Baatenburg de Jong RJ: HGF and c-MET as potential orchestrators of invasive growth in head and neck squamous cell carcinoma. Front Biosci 13: 2516-2526, 2008.

27. Freudlsperger C, Alexander D, Reinert S and Hoffmann J: Prognostic value of c-Met expression in oral squamous cell carcinoma. Exp Ther Med 1: 69-72, 2010.
28. Hanzawa M, Shindoh M, Higashino F, Yasuda M, Inoue N, Hida K, Ono M, Kohgo T, Nakamura M, Notani K, et al: Hepatocyte growth factor upregulates E1AF that induces oral squamous cell carcinoma cell invasion by activating matrix metalloproteinase genes. Carcinogenesis 21: 1079-1085, 2000.

29. Murai M, Shen X, Huang L, Carpenter WM, Lin CS, Silverman S, Regezi J and Kramer RH: Overexpression of c-met in oral SCC promotes hepatocyte growth factor-induced disruption of cadherin junctions and invasion. Int J Oncol 25: 831-840, 2004.

30. Kim CH, Koh YW, Han JH, Kim JW, Lee JS, Baek SJ, Hwang HS and Choi EC: c-Met expression as an indicator of survival outcome in patients with oral tongue carcinoma. Head Neck 32: 1655-1664, 2010

31. Lim YC, Kang HJ and Moon JH: C-Met pathway promotes self-renewal and tumorigenecity of head and neck squamous cell carcinoma stem-like cell. Oral Oncol 50: 633-639, 2014.

32. Hartmann S, Bhola NE and Grandis JR: HGF/Met signaling in head and neck cancer: Impact on the tumor microenvironment. Clin Cancer Res 22: 4005-4013, 2016.

33. Lim YC, Han JH, Kang HJ, Kim YS, Lee BH, Choi EC and $\mathrm{Kim} \mathrm{CH}$ : Overexpression of c-Met promotes invasion and metastasis of small oral tongue carcinoma. Oral Oncol 48: 1114-1119, 2012.

34. Tao X, Hill KS, Gaziova I, Sastry SK, Qui S, Szaniszlo P, Fennewald S, Resto VA and Elferink LA: Silencing Met receptor tyrosine kinase signaling decreased oral tumor growth and increased survival of nude mice. Oral Oncol 50: 104-112, 2014.

35. Yao HP, Zhou YQ, Zhang R and Wang MH: MSP-RON signalling in cancer: Pathogenesis and therapeutic potential. Nat Rev Cancer 13: 466-481, 2013.

36. Ma PC, Tretiakova MS, Nallasura V, Jagadeeswaran R, Husain AN and Salgia R: Downstream signalling and specific inhibition of c-MET/HGF pathway in small cell lung cancer: Implications for tumour invasion. Br J Cancer 97: 368-377, 2007.

37. Liu X, Newton RC and Scherle PA: Developing c-MET pathway inhibitors for cancer therapy: Progress and challenges. Trends Mol Med 16: 37-45, 2010.

38. Matsumoto $\mathrm{K}$ and Nakamura T: Hepatocyte growth factor and the Met system as a mediator of tumor-stromal interactions. Int $\mathrm{J}$ Cancer 119: 477-483, 2006.

39. You WK and McDonald DM: The hepatocyte growth factor/c-Met signaling pathway as a therapeutic target to inhibit angiogenesis. BMB Rep 41: 833-839, 2008.

40. Zeng Q, Chen S, You Z, Yang F, Carey TE, Saims D and Wang CY: Hepatocyte growth factor inhibits anoikis in head and neck squamous cell carcinoma cells by activation of ERK and Akt signaling independent of NFkappa B. J Biol Chem 277: 25203-25208, 2002.

41. Zeng Q, McCauley LK and Wang CY: Hepatocyte growth factor inhibits anoikis by induction of activator protein 1-dependent cyclooxygenase-2. Implication in head and neck squamous cell carcinoma progression. J Biol Chem 277: 50137-50142, 2002.

42. Rosen EM and Goldberg ID: Scatter factor and angiogenesis. Adv Cancer Res 67: 257-279, 1995.

43. Dong G, Chen Z, Li ZY, Yeh NT, Bancroft CC and Van Waes C: Hepatocyte growth factor/scatter factor-induced activation of MEK and PI3K signal pathways contributes to expression of proangiogenic cytokines interleukin- 8 and vascular endothelial growth factor in head and neck squamous cell carcinoma. Cancer Res 61: 5911-5918, 2001.

44. Michi Y, Morita I, Amagasa T and Murota S: Human oral squamous cell carcinoma cell lines promote angiogenesis via expression of vascular endothelial growth factor and upregulation of KDR/flk-1 expression in endothelial cells. Oral Oncol 36: $81-88,2000$.

45. Sequist LV, von Pawel J, Garmey EG, Akerley WL, Brugger W, Ferrari D, Chen Y, Costa DB, Gerber DE, Orlov S, et al: Randomized phase II study of erlotinib plus tivantinib versus erlotinib plus placebo in previously treated non-small-cell lung cancer. J Clin Oncol 29: 3307-3315, 2011

46. Smith DC, Smith MR, Sweeney C, Elfiky AA, Logothetis C, Corn PG, Vogelzang NJ, Small EJ, Harzstark AL, Gordon MS, et al: Cabozantinib in patients with advanced prostate cancer: Results of a phase II randomized discontinuation trial. J Clin Oncol 31: 412-419, 2013. 